\title{
The Role of Platelet Rich Plasma in Comparison with Corticosteroids in the Treatment of De Quervain Tenosynovitis
}

\author{
EMAN A. EL SHEIKH, M.Sc.*; SOBHIA A. MAHMOUD, M.D.** and MARWA M. ABD EL-RAHIM, M.D.** \\ The Department of Rheumatology and Rehabilitation, Faculty of Medicine, Alexandria University* and \\ Al-Azhar University for Girls**
}

\begin{abstract}
Background: De Quervain's disease (DQVD) is the stenosing tenosynovitis of tendons in the first extensor compartment. Its diagnosis is made clinically by Finkelstein test. Musculoskeletal ultrasound (MSUS) is used to confirm the diagnosis and for the follow-up after injection. One of the non-surgical strategies of treatment is platelet rich plasma (PRP) injection.
\end{abstract}

Aim of Study: To evaluate the effects of PRP in the treatment of DQVD in comparison with corticosteroid (CS) injection.

Subjects and Methods: 40 hands of 35 patients were included. 20 hands received single CS injection (group I) and the other 20 hands were injected with PRP (group II). Patients were evaluated using Visual analogue scale (VAS), Jebsen Hand Function Test (JHFT), the shortened disabilities of the arm, shoulder and hand questionnaire (Quick DASH), and the examination of the contents of the first dorsal compartment by MSUS at baseline, one and six months after the injection. Healthy side of patients were considered as control group (30 hands).

Results: Overall, 31 females and 4 males were included with 20 hands in each group. The CS group had better pain relief, hand function tests and ultrasonograghic findings at 1 month, but at 6 months follow-up, the PRP group had statistically significant better pain relief, hand function tests and US findings than CS group.

Conclusion: PRP injection is an effective treatment option for those patients with DQVD. The patients improved in pain intensity, disability and ultrasound findings. It is better than CS in the intermediate term by its ability to induce self-healing with no side effects.

Key Words: DQVD - Platelet rich plasma-Corticosteroids $-M S U S$.

\section{Introduction}

DE QUERVAIN tenosynovitis is a condition named after the Swiss surgeon Fritz De Quervain

Correspondence to: Dr. Eman A. El Sheikh, E-Mail: e.elshikh2008@gmail.com in 1895 who published his five case reports of patients with a tender, thickened first dorsal compartment at the wrist $[\mathbf{1 , 2}]$. DQVD is an entrapment tendinitis of the tendons within the first dorsal compartment of the wrist. The first dorsal compartment of the wrist includes tendons of the abductor pollicis longus (APL) and the extensor pollicis brevis (EPB) [3]

Most patients respond well to non-operative management, which includes immobilization of the thumb, non-steroidal anti-inflammatory drugs, physiotherapy, and local corticosteroid injection [4]

US-guided DQVD injection improves injection accuracy through the visualization of compartmental anatomy, needle placement and may improve clinical outcomes by minimizing complications associated with extra-compartmental injection [5]

Corticosteroid injection is frequently used for the control of inflammation in De Quervain's disease, the incidence of complications after local corticosteroid injection is extremely low with an estimated risk of less than $1 \%$ [6]

Platelet-rich plasma (PRP) injections are nowadays being used as an alternative for treating the tendinopathies, who have failed to be managed by conservative management. PRP is a currently used strategy in the clinical practice to provide a regenerative stimulus for tendon healing [7]. PRP is a set of autologous platelet products used to reduce pain and speed up recovery from injury while maintaining the tissue function. Its basic role is to mimic and enhance the natural processes of healing by bringing to the injury site a set of molecules that will accelerate functional recovery, and even regenerate the tissue [8]. It is derived by centrifu- 
gation of the whole blood, has a platelet concentration higher than that of the whole blood, platelet is the cellular component of plasma that settles after centrifugation, and contains numerous growth factors [9]

Due to availability from patients' whole blood and thus its autologous source, makes it theoretically and potentially safe, without risks of disease transmission or immunogenic reaction [10]

\section{Aim of the work:}

To evaluate the effect of platelet rich plasma in the treatment of De Quervain'stenosynovitis in comparison to corticosteroid local injection.

\section{Patients and Methods}

Forty hands of 35 patients with symptoms and signs suggestive of DQVD were recruited from outpatient clinic of Rheumatology and Rehabilitation at A-Zahraa University Hospital, after a written informed consent from all patients, and approval of the medical ethics committee of AlAzhar University and conforms to the Helsinki declaration.

The patients' hands were divided into two groups, Group I (CS): Included 20 hands which received single CS injection with $1 \mathrm{ml}$ betamethasone. Two patients were males and 16 patients were females, their age ranged from 27 to 54 years. Group II (PRP): Included 20 hands which received PRP injection, 2 patients were males and 15 patients were females, their age ranged from 23-59 years.

To prepare PRP, we collected blood sample into an $8.5 \mathrm{ml}$ vacutainer tube with acid citrate dextrose anticoagulant. The blood was spun in a centrifuge (Cooling Centrifuge AIO. Code T052649 ) at $900 \mathrm{rpm}$ for $10 \mathrm{~min}$ and $1.5 \mathrm{ml}$ was siphoned from the buffy coat layer by a 21 gauge syringe and injected by guided ultrasound into the tendon sheath. Patients were advised to avoid any physical activity for the next 48 hours and were allowed to ice the wrist joint and take paracetamol as necessary, but to avoid non steroidal anti-inflammatory drugs.

All patients were evaluated at baseline, after 1 month and after 6 months of either PRP or corticosteroid injection. They were subjected to clinical evaluation, evaluation of pain using a 0-10 Visual analogue scale (VAS), hand function evaluation by Jebsen Hand Function Test (JHFT), and the shortened disabilities of the arm, shoulder and hand questionnaire (Quick DASH), andfinally the examination of the contents of the first dorsal compartment by MSUS Xario200, Toshiba ultrasound machine (Toshiba, Toshiba medical systems corporation, Tochigi, Japan), using multi frequency linear probe with frequency 11 Mega Hertz in Bmode).

Ultrasonographic evaluation included tendon thickness, combined tendon and sheath thickness, extensor retinaculum thickness and the presence or absence of effusion. Unfortunately 7 patients were lost during the follow-up at (6 months), (5 patients were lost in CS group and 2 patients were lost in PRP group). Also we examined the healthy sides of all patients (30 hands) and considered them as a control group to compare ultrasound findings except for patients who were affected bilaterally.

Inclusion criteria: (1) Over the age of eighteen. (2) Diagnosis of De Quervain's tenosynovitis based on combination of clinical symptoms, signs and abnormal finding in MSUS. (3) Patients with failed conservative treatment were also included in this study.

With exclusion criteria: (1) History of rheumatic disease. (2) History of trauma or fracture in the hand or the wrist joint. (3) History of endocrinal disease as Diabetes mellitus and thyroid disorder. (4) Pregnancy. (5) Previous corticosteroid injection for treatment of De Quervain's disease. (6) Any shoulder or elbow problems that might lead to misdiagnosis.

Statistical analysis: Recorded data were analyzed using the statistical package for social sciences, version 20.0 (SPSS Inc., Chicago, Illinois, USA). Quantitative data were expressed as mean \pm standard deviation (SD). Qualitative data were expressed as frequency and percentage. The following tests were done: $t$-test, ANOVA, LSD and Chi-square $\left(\mathrm{x}^{2}\right)$ test. $p$-value $\leq 0.05$ was considered significant.

\section{Results}

The present study was conducted on 40 hands with DQVD, the patients characteristics are shown in Table (1). The patients were divided into two groups according to the type of injection they received, group I received CS injection, and group II received PRP injection. The healthy side of patients were considered as a control group (30 hands). 
Table (1): Demographic characteristic of the studied cases.

\begin{tabular}{llll}
\hline $\begin{array}{l}\text { Demographic } \\
\text { data }\end{array}$ & $\begin{array}{c}\text { Group I } \\
\text { Mean } \pm \text { SD }(\%) \\
(\mathrm{n}=18)\end{array}$ & $\begin{array}{c}\text { Group II } \\
\text { Mean } \pm \text { SD }(\%) \\
(\mathrm{n}=17)\end{array}$ & $\begin{array}{c}p- \\
\text { value }\end{array}$ \\
\hline Age (years) & $41.30 \pm 8.06$ & $41.45 \pm 11.54$ & 0.906 \\
$\begin{array}{l}\text { Sex: } \\
\text { Female }\end{array}$ & $16(90.0 \%)$ & $15(90.0 \%)$ & 0.91 \\
Male & $2(10.0 \%)$ & $2(10.0 \%)$ & \\
Occupation: & & & \\
Carpenter & $0(0.0 \%)$ & $1(5.0 \%)$ & 0.351 \\
Dressmaker & $0(0.0 \%)$ & $1(10.0 \%)$ & \\
Employer & $1(5.0 \%)$ & $0(0.0 \%)$ & \\
House wife & $14(75.0 \%)$ & $13(75.0 \%)$ & \\
Nurse & $2(15.0 \%)$ & $1(5.0 \%)$ & \\
Seller & $1(5.0 \%)$ & $0(0.0 \%)$ & \\
Typist & $0(0.0 \%)$ & $1(5.0 \%)$ & \\
Duration (months) & $6.98 \pm 5.85$ & $5.80 \pm 3.74$ & 0.454 \\
& & & \\
Dominant hand: & & & \\
Lt & $1(5.5 \%)$ & $3(17.6 \%)$ & 0.598 \\
Rt & $17(94.4 \%)$ & $14(82.3 \%)$ & \\
Affected hand: & & & 0.421 \\
Bilateral & $2(11.1 \%)$ & $3(17.6 \%)$ & \\
Lt & $2(11.1 \%)$ & $4(23.5 \%)$ & \\
Rt & $14(77.7 \%)$ & $10(58.8 \%)$ & \\
\hline & & & \\
\hline
\end{tabular}

As regards the mean difference in Visual Analogue Scale (VAS) between the baseline evaluation and after 1 month of injection, there was a statistically highly significant difference between group I and group II with more reduction in VAS score in group I. While there was a statistically highly significant difference between group I and group II as regards the mean difference between the results after 1 and 6 months of injection, with more reduction in VAS score in group II Table (2) and Fig (1).

Table (2): Showing comparison between group I and group II regarding VAS.

\begin{tabular}{lccc}
\hline & $\begin{array}{c}\text { Group I } \\
(\mathrm{Mean} \pm \mathrm{SD}) \\
(\mathrm{n}=20)\end{array}$ & $\begin{array}{c}\text { Group II } \\
(\mathrm{Mean} \pm \mathrm{SD}) \\
(\mathrm{n}=20)\end{array}$ & $p$-value \\
\hline VAS $(0-10):$ & & & \\
Baseline & $7.65 \pm 1.93$ & $7.70 \pm 1.95$ & $0.935 \mathrm{NS}$ \\
After 1 month & $0.55 \pm 1.05$ & $2.65 \pm 2.98$ & $0.005 * \mathrm{~S}$ \\
After 6 months & $2.13 \pm 2.75$ & $1.94 \pm 3.04$ & $0.034^{*} \mathrm{~S}$ \\
$\quad(\mathrm{GI} n=15$, GII $\mathrm{n}=18)$ & & & \\
Mean difference between: & & & \\
Before and after 1m & $-7.10 \pm 1.42$ & $-5.05 \pm 1.01$ & $<0.001 * * \mathrm{HS}$ \\
After 1m and 6m & $1.58 \pm 0.32$ & $-0.71 \pm 0.14$ & $<0.001 * * \mathrm{HS}$ \\
\hline
\end{tabular}

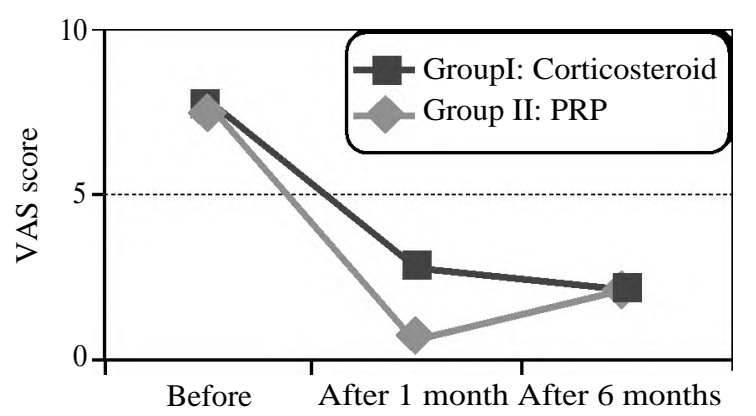

Fig (1): A chart showing follow-up of VAS of group I and group II at (0), (1) \& (6) months after injection.
As regards the mean difference of the shortened disabilities of the arm, shoulder and hand questionnaire (Quick DASH) between the baseline evaluation and after 1 month of injection, there was a statistically significant difference between group I and group II with more improvement in DASH score in group I. While Jebsen Hand Function Test (JHFT) showed a statistically highly significant difference between the two groups with more improvement in the PRP group. By comparing the mean difference after $1 \& 6$ months of injection, there was more improvement in both hand function tests (qDASH and JHFT tests) in group II, with highly significant difference (Table 3) and (Fig. 2).

Table (3): Showing comparison between group I and group II regarding hand function tests, qDASH and JHFT.

\begin{tabular}{|c|c|c|c|}
\hline & $\begin{array}{c}\text { Group I } \\
(\text { Mean } \pm \text { SD) } \\
(\mathrm{n}=20)\end{array}$ & $\begin{array}{c}\text { Group II } \\
(\text { Mean } \pm \text { SD) } \\
(\mathrm{n}=20)\end{array}$ & $p$-value \\
\hline \multicolumn{4}{|l|}{$q D A S H(0-100):$} \\
\hline Baseline & $34.52 \pm 8.13$ & $36.45 \pm 8.67$ & $0.473 \mathrm{~ns}$ \\
\hline After 1 month & $5.34 \pm 3.48$ & $11.13 \pm 13.04$ & $0.043 * \mathrm{~s}$ \\
\hline $\begin{array}{l}\text { After } 6 \text { months } \\
\quad(\mathrm{GI} n=15),(\mathrm{GII} n=18)\end{array}$ & $10.90 \pm 10.86$ & $9.38 \pm 13.52$ & $0.729 \mathrm{~ns}$ \\
\hline $\begin{array}{l}\text { Mean difference between: } \\
\text { Baseline and after } 1 \mathrm{~m} \\
\text { After } 1 \mathrm{~m} \text { and } 6 \mathrm{~m}\end{array}$ & $\begin{array}{l}-29.18 \pm 5.84 \\
5.56 \pm 1.11\end{array}$ & $\begin{array}{l}-25.32 \pm 5.06 \\
-1.75 \pm 0.35\end{array}$ & $\begin{array}{c}0.031 * \mathrm{~S} \\
<0.001 * * \mathrm{HS}\end{array}$ \\
\hline JHFT: & & $60.95 \pm 7.88$ & $0.013 * \mathrm{~s}$ \\
\hline Baseline & $54.38 \pm 8.16$ & $52.31 \pm 7.63$ & $0.037 * \mathrm{~s}$ \\
\hline After 1 month & $47.84 \pm 5.27$ & & \\
\hline $\begin{array}{l}\text { After } 6 \text { months } \\
\qquad(\mathrm{GI} n=15),(\mathrm{GII} n=18)\end{array}$ & $49.56 \pm 5.98$ & $50.39 \pm 7.63$ & $0.735 \mathrm{~ns}$ \\
\hline \multicolumn{4}{|l|}{ Mean difference between: } \\
\hline Baseline and after 1m & $-6.54 \pm 1.31$ & $-8.64 \pm 1.73$ & $<0.001 * * \mathrm{HS}$ \\
\hline After $1 \mathrm{~m}$ and $6 \mathrm{~m}$ & $1.72 \pm 0.34$ & $-1.92 \pm 0.38$ & $<0.001 * * \mathrm{HS}$ \\
\hline
\end{tabular}
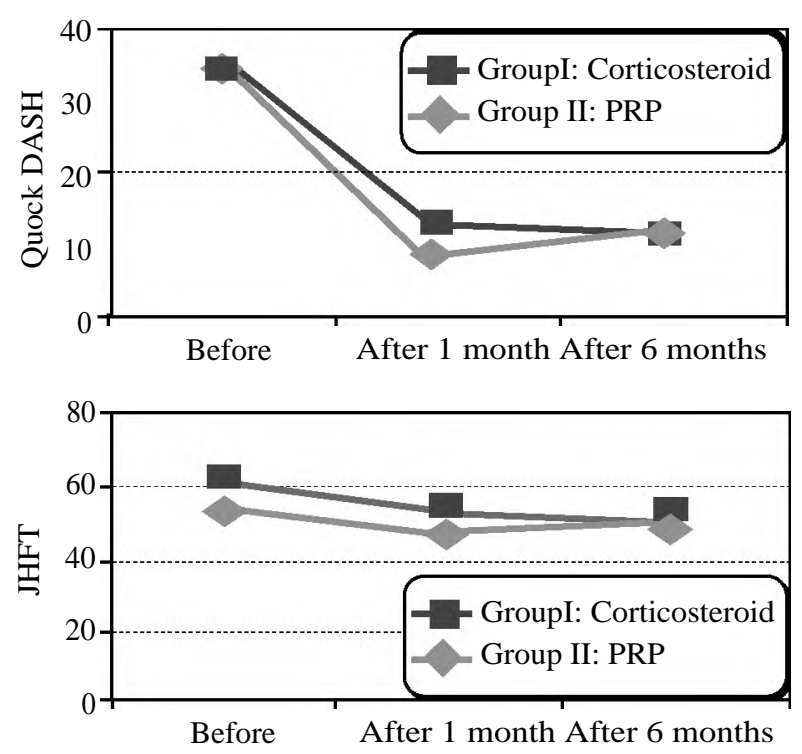

Fig (2): A chart showing follow-up of group I and group II regarding quick DASH and JHFT at (0), (1) \& (6) months after injection. 
In the present study, Ultrasonographic findings showed highly statistically significant difference between group I, group II compared to the control group regarding tendon thickness, combined tendon and sheath thickness and extensor retinaculum (ER) thickness, with all mean values higher in group I and II in comparison to the control group Table (4) and Fig. (3).

Table (4): Comparison between groups (I) \& (II) and the control group regarding tendon thickness, combined tendon and sheath thickness and ER thickness at baseline.

\begin{tabular}{|c|c|c|c|c|}
\hline & $\begin{array}{c}\text { Group I } \\
\text { Mean } \pm \text { SD } \\
(n=20)\end{array}$ & $\begin{array}{c}\text { Group II } \\
\text { Mean } \pm \text { SD } \\
(\mathrm{n}=20)\end{array}$ & $\begin{array}{c}\text { Control Group } \\
\text { Mean } \pm \text { SD } \\
(n=30)\end{array}$ & $p$-value \\
\hline \multicolumn{5}{|l|}{$\begin{array}{l}\text { Baseline } \\
\text { tendon } \\
\text { thickness: }\end{array}$} \\
\hline LS & $3.10 \pm 1.02$ & $2.55 \pm 0.62 \mathbf{a}$ & $1.93 \pm 0.35^{\mathbf{a b}}$ & $<0.001 * * \mathrm{HS}$ \\
\hline $\mathrm{TS}$ & $3.36 \pm 0.99$ & $3.13 \pm 0.67$ & $2.26 \pm 0.42^{\mathbf{a b}}$ & $<0.001 * * \mathrm{HS}$ \\
\hline \multicolumn{5}{|l|}{$\begin{array}{l}\text { Baseline } \\
\text { tendon \& } \\
\text { sheath } \\
\text { thickness }\end{array}$} \\
\hline LS & $4.46 \pm 1.24$ & $3.96 \pm 1.03$ & $2.53 \pm 0.36^{\mathbf{a b}}$ & $<0.001 * *$ \\
\hline $\mathrm{TS}$ & $4.55 \pm 1.43$ & $4.23 \pm 0.89$ & $2.96 \pm 0.36^{\mathbf{a b}}$ & $<0.001 * *$ \\
\hline $\begin{array}{l}\text { Baseline } \\
\text { ER } \\
\text { thickness } \\
(\mathrm{mm})\end{array}$ & $1.30 \pm 0.47$ & $1.20 \pm 0.45$ & $0.45 \pm 0.00^{\mathbf{a b}}$ & $<0.001 * *$ \\
\hline
\end{tabular}

a: Significant difference with group I.

b: Significant difference with group B.

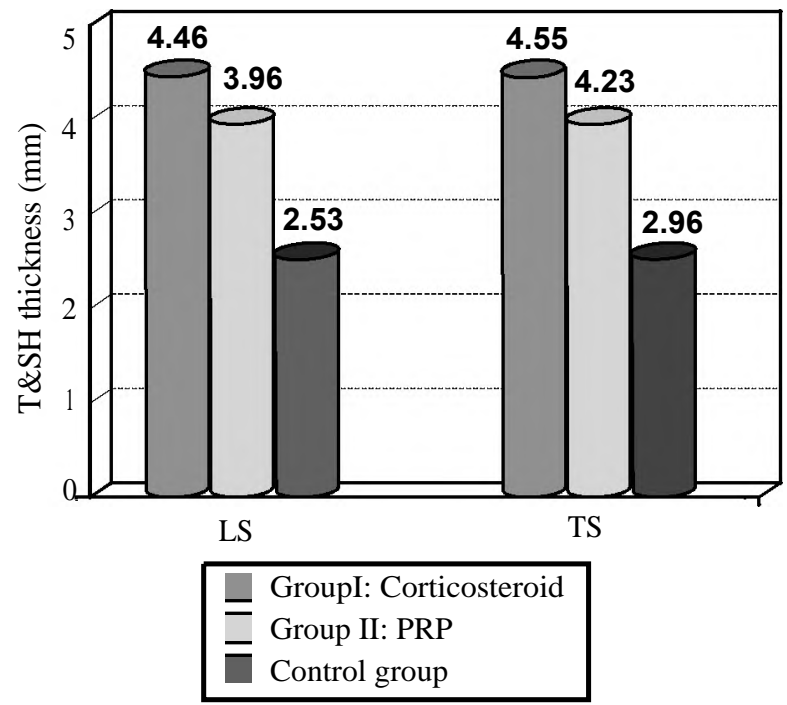

Fig (3): Bar chart showing comparison between groups (I) \& (II) and the control group regarding tendon and sheath thickness.

By comparing the mean difference of tendon thickness and combined tendon and sheath thickness in both longitudinal and transverse sections, at baseline and after 1 month of injection, there was ahighly statistically significant differencebetween the two groups with more reduction in thickness in group I, while ER showed no significant difference.

On the other hand there was more improvement in all ultrasonographic findings (tendon thickness, combined tendon and sheath thickness and ER thickness) in the PRP group than the CS group with highly significant difference between the two groups on comparing the results after 1 and 6 months of followup Table (5) and Fig. (4).

Table (5): Comparison between groups (I) \& (II) and the control group regarding tendon thickness, combined tendon and sheath thickness and ER thickness at baseline.

\begin{tabular}{|c|c|c|c|}
\hline & $\begin{array}{c}\text { Group I } \\
(\text { Mean } \pm \text { SD }) \\
(\mathrm{n}=20)\end{array}$ & $\begin{array}{c}\text { Group II } \\
(\text { Mean } \pm \text { SD }) \\
(\mathrm{n}=20)\end{array}$ & $p$-value \\
\hline \multicolumn{4}{|l|}{$\begin{array}{l}\text { Baseline tendon } \\
\text { thickness }(\mathrm{mm}) \text { : }\end{array}$} \\
\hline LS & $3.10 \pm 1.02$ & $2.55 \pm 0.62 \mathbf{a}$ & $0.061 \mathrm{NS}$ \\
\hline $\mathrm{TS}$ & $3.36 \pm 0.99$ & $3.13 \pm 0.67$ & $0.564 \mathrm{NS}$ \\
\hline \multicolumn{4}{|l|}{ After 1 month: } \\
\hline LS & $2.18 \pm 0.58$ & $2.14 \pm 0.80$ & $0.857 \mathrm{NS}$ \\
\hline TS & $2.37 \pm 0.59$ & $2.60 \pm 0.80$ & $0.318 \mathrm{NS}$ \\
\hline \multicolumn{4}{|l|}{$\begin{array}{l}\text { After } 6 \text { month } \\
(G I n=15), \\
(G I I n=18) \text { : }\end{array}$} \\
\hline LS & $2.35 \pm 0.77$ & $1.99 \pm 0.53$ & $0.133 \mathrm{NS}$ \\
\hline $\mathrm{TS}$ & $2.54 \pm 0.67$ & $2.42 \pm 0.57$ & $0.571 \mathrm{NS}$ \\
\hline \multicolumn{4}{|l|}{ LS difference between: } \\
\hline Baseline and after $1 \mathrm{~m}$ & $-0.92 \pm 0.18$ & $-0.41 \pm 0.08$ & $<0.001 * * \mathrm{HS}$ \\
\hline After $1 \mathrm{~m}$ and $6 \mathrm{~m}$ & $0.17 \pm 0.03$ & $-0.15 \pm 0.03$ & $<0.001 * * \mathrm{HS}$ \\
\hline \multicolumn{4}{|l|}{ TS difference between: } \\
\hline Baseline and after $1 \mathrm{~m}$ & $-0.99 \pm 0.20$ & $-0.53 \pm 0.11$ & $<0.001 * * \mathrm{HS}$ \\
\hline After $1 \mathrm{~m}$ and $6 \mathrm{~m}$ & $0.17 \pm 0.03$ & $-0.18 \pm 0.04$ & $<0.001 * * \mathrm{HS}$ \\
\hline \multicolumn{4}{|l|}{$\begin{array}{l}\text { Baseline tendon } \\
\text { and sheath }\end{array}$} \\
\hline \multicolumn{4}{|l|}{ thickness $(\mathrm{mm})$ : } \\
\hline LS & $4.46 \pm 1.24$ & $3.96 \pm 1.03$ & $0.175 \mathrm{NS}$ \\
\hline TS & $4.55 \pm 1.43$ & $4.23 \pm 0.89$ & $0.401 \mathrm{NS}$ \\
\hline \multicolumn{4}{|l|}{ After 1 month: } \\
\hline TS & $3.26 \pm 0.78$ & $3.46 \pm 0.97$ & $0.476 \mathrm{NS}$ \\
\hline \multicolumn{4}{|l|}{$\begin{array}{l}(G I n=15), \\
(G I I n=18):\end{array}$} \\
\hline LS & $3.23 \pm 0.92$ & $2.91 \pm 0.96$ & $0.335 \mathrm{NS}$ \\
\hline $\mathrm{TS}$ & $3.53 \pm 0.87$ & $3.18 \pm 0.63$ & $0.183 \mathrm{NS}$ \\
\hline \multicolumn{4}{|l|}{ LS difference between: } \\
\hline Baseline and after $1 \mathrm{~m}$ & $-1.47 \pm 0.29$ & $-0.98 \pm 0.20$ & $<0.001 * * \mathrm{HS}$ \\
\hline After $1 \mathrm{~m}$ and $6 \mathrm{~m}$ & $0.24 \pm 0.05$ & $-0.07 \pm 0.01$ & $<0.001 * * \mathrm{HS}$ \\
\hline \multicolumn{4}{|l|}{ TS difference between: } \\
\hline Baseline and after $1 \mathrm{~m}$ & $-1.29 \pm 0.26$ & $-0.77 \pm 0.15$ & $<0.001 * * \mathrm{HS}$ \\
\hline After $1 \mathrm{~m}$ and $6 \mathrm{~m}$ & $0.27 \pm 0.05$ & $-0.28 \pm 0.06$ & $<0.001 * * \mathrm{HS}$ \\
\hline \multicolumn{4}{|l|}{$\begin{array}{l}\text { Baseline ER } \\
\text { thickness }(\mathrm{mm}) \text { : }\end{array}$} \\
\hline & $1.30 \pm 0.47$ & $1.20 \pm 0.45$ & $<0.001 * * \mathrm{HS}$ \\
\hline After 1 month & $0.86 \pm 0.34$ & $0.79 \pm 0.31$ & $0.506 \mathrm{NS}$ \\
\hline After 6 months & $0.98 \pm 0.35$ & $0.59 \pm 0.25$ & $<0.001 * * \mathrm{HS}$ \\
\hline \multicolumn{4}{|l|}{ Mean difference between: } \\
\hline Baseline and after $1 \mathrm{~m}$ & $-0.44 \pm 0.09$ & $-0.41 \pm 0.08$ & $0.272 \mathrm{NS}$ \\
\hline After $1 \mathrm{~m}$ and $6 \mathrm{~m}$ & $0.12 \pm 0.02$ & $-0.2 \pm 0.04$ & $<0.001 * * \mathrm{HS}$ \\
\hline
\end{tabular}



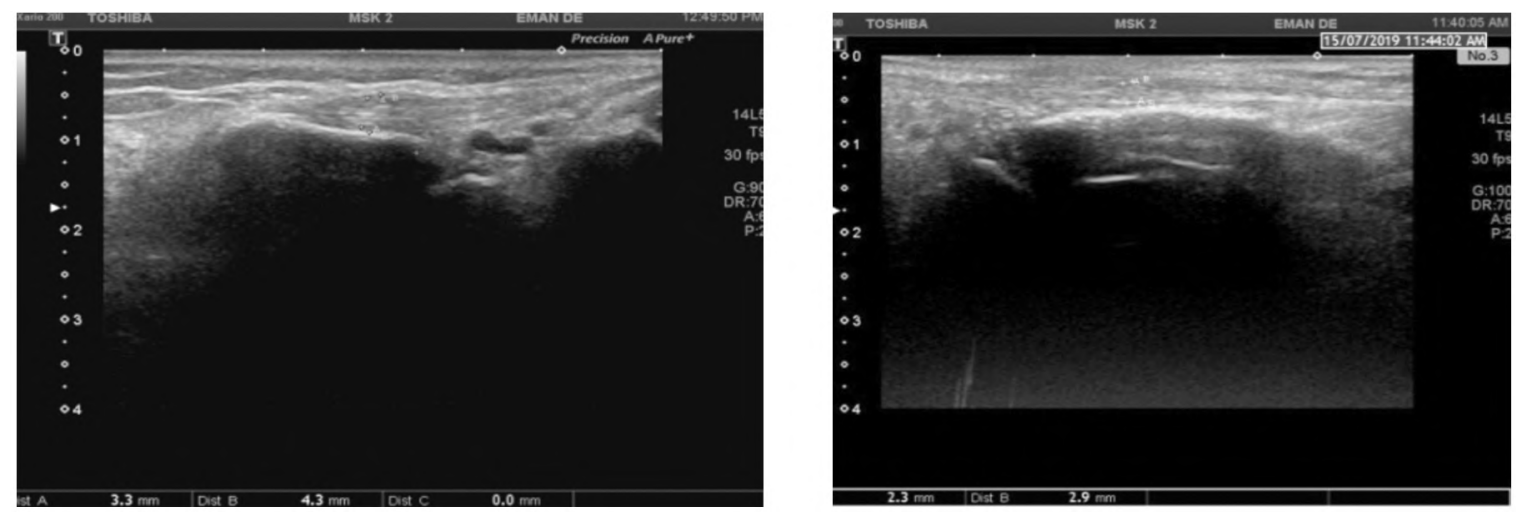

Fig. (4): Showing tendon thickness and combined tendon and sheath thickness of the 1stextensor compartement in LS before and after injection.

Regarding the presence of effusion in the tendon sheath, $40 \%$ of patients had effusion in group I at baseline. After 1 month of injection only 5\% of patients had effusion, while after 6 months $20 \%$ had effusion. In group II, $45 \%$ of patients had effusion at baseline. After 1 month $10 \%$ of patients had effusion, while after 6 months $11.1 \%$ had effusion.

\section{Discussion}

DQVD is the stenosing tenosynovitis of tendons in the first extensor compartment of the wrist. People who use their hands frequently as in cooking, piano playing, knitting, typing, working in the garden, playing golf, or lifting baby are more risky to have DQVD [11,12] .

Platelet-rich plasma (PRP) is autologous blood centrifuged to produce a smaller volume of more concentrated platelets. Prior studies have shown success when using PRP to treat tendinopathies, including Achilles tendinopathy, elbow epicondylar tendinopathy, patellar tendinopathy and rotator cuff tendinopathy [13].

Our study has been proposed to determine the effect of Platelet-rich plasma (PRP) in De Quervain's disease in comparison to corticosteroid local injection.

In the current study, the patients were divided into two groups, Group I: Corticosteroid (CS) group, patients received single US guided CS injection. Group II: (PRP) group, patients received single US guided PRP injection. We collected blood sample into an $8.5 \mathrm{ml}$ vacutainer tube with acid citrate dextrose anticoagulant. The blood was spun in a centrifuge at $900 \mathrm{rpm}$ for $10 \mathrm{~min}$ and $1.5 \mathrm{ml}$ was siphoned from the buffy coat layer. This protocol was used in a previous study for the treatment of resistant elbow tendinopathy [14]
In our study the patients were injected once and this coincided with a study on the effect of PRP as a treatment of DQVD in thirty patients who received single injection of PRP [15]. Also in a previous study for the treatment of lateral epicondylitis, they stated that single PRP injection may be sufficient and no great differences were found in results between cases injected once and others injected twice or more [16]. While in a former research, they injected chronic Achilles tendinopathy 3 times at 2-weeks intervals [17].

In the present study, regarding pain assessment by (VAS) grading from (0-10), there was a statistically highly significant difference between group I (CS) and group II (PRP) as regards the mean difference between the baseline evaluation and after 1 month of injection with more reduction in VAS score in CS group. While by comparing the mean difference after $1 \& 6$ months of injection, there was a higher decline in VAS in group II with highly significant difference between the two groups. These results denote more improvement of VAS after 6 months of follow-up in PRP group and so PRP is more beneficial than CS on the intermediate term.

This is in agreement with a previous study, which included 33 patients with DQVD, injected with CS and found that the mean VAS at baseline was $(8.6 \pm 1.1)$ but after 3 weeks follow-up it was $(1.3 \pm 1.3)[18]$.

A previous study found that the initial VAS score was 9.42 in the studied 141 patients with DQVD, and the mean post-procedural 6 months VAS was 3.92, a statistically significant improvement was observed in terms of pain relief after a single PRP injection in DQVD [19].

Also we agreed with a retrospective study which depended on pain evaluation in DQVD. The study 
included 30 patients who were injected once by PRP. And reported decrease of the mean VAS from 5.9 to 2 after 6 months of follow-up, and increase in the pain free movement in all ranges without any significant complications [20].

There was a statistically significant difference between group I (CS) and group II (PRP) as regards the mean difference between the baseline and after 1 month of injection with more reduction in Quick DASH score in CS group. While by comparing the mean differenceafter $1 \& 6$ months, there was a higher decline in the mean difference in the PRP group compared to the CS group with highly significant difference between the two groups. These results denote more improvement of Quick DASH after 6 months of follow-up in the PRP group and that PRP has more sustained effect than the CS on the intermediate term.

There was a statistically highly significant difference between group I and group II as regards the mean difference between baseline ( 0$)$ and after 1 month of injection (with more reduction in score of JHFT in the PRP group). While the mean difference between the results after $1 \& 6$ months, showed a highly significant difference between the two groups with more reduction in JHFT in the PRP group than the CS group.

A previous study used JHFT to assess hand function and found that the average time to complete the JHFT test was significantly increased $(p<0.05)$ for both the highly and partially restricted wrists [23]

These results are in agreement with a study on chronic tendinopathy that included 6 cases of DQVD managed with ultrasound-guided plateletrich plasma infiltration, and found that the mean baseline qDASH was 54.16, after 1 month followup it was 47.4, and after 6 months it was 22.9 with $57.63 \%$ decrease in qDASH [21]. Also in a previous research on Lateral epicondylitis, they found that the mean qDASH at the baseline was ( 88 vs. 88 ) in PRP group and CS group respectively. After 1 month it was (62.5 vs. 53.13) in PRP and corticosteroid group respectively with lower score in CS group, after 3 months it was ( 34.16 vs. 44.33 ) with more reduction of score in the PRP group with highly significant difference between the two groups. This is in agreement with our study [22]

In the present study, Ultrasonographic findings showed highly statistically significant difference between group I, group II compared to the control group regarding tendon thickness denoting tendinopathy, combined tendon and sheath thickness denoting tenosynovitis and increased extensor retinaculum thickness.

As regards the mean difference in tendon thickness and combined tendon and sheath thickness, by comparing the results at baseline and after 1 month of follow-up, we found a highly significant difference between group I \& II with more reduction in thickness in LS \& TS in group I (CS group). While ER thickness showed no significant difference. On the other hand, by comparing the mean difference in the tendon thickness, the combined tendon and sheath thickness and the ER thickness after 1 and 6 months follow-up; there was more decrease in the thickness of all parameters in the PRP group than the CS group with highly significant difference between the two groups. These results denote more improvement in US finding after PRP injection and that PRP benefits are more sustainable than CS on the intermediate term.

In a previous case report, they measured the changes in tendon thickness in a female patient with DQVD after receiving methotrexate injection, and they found that the tendon thickness decreased in size (from 5.5 to $5.1 \mathrm{~mm}$ ) in comparison with images taken before methotrexate injections [24] In another study which monitored the changes in the tendon sheath after ultrasound guided local steroid injection in twenty one patients with a clinical diagnosis of DQVD, a significant decrease in the thickness of the tendon sheath was seen after one week of the local corticosteroid injection, Complete relief of symptoms and signs was further observed at 6 and 12 weeks. This is in agreement with our study [25].

Also in a previous research which studied 25 patients with DQVD injected with $1 \mathrm{ml}$ methylprednisolone acetate, and they found that the mean baseline ER thickness was $1.6 \mathrm{~mm}$, after 3 months follow-up, the mean retinaculum thickness was $0.7 \mathrm{~mm}$, and after 6 months the mean ER thickness was $1.5 \mathrm{~mm}$. This is in agreement with our results regarding the short term effects of CS on ER thickness [26]

So PRP injection in DQVD is considered a successful alternative treatment of healing effect, reducing pain with no side effects. We found that this treatment gives the maximum efficacy in the intermediate term, while CS has short term effect. No side effects were reported, no hypersensitivity, allergy or infection. This confirmed the efficacy and safety of PRP injection in the treatment of DQVD. 


\section{Conclusion and recommendations:}

PRP is an effective strategy in the treatment of De Quervain's disease that improved pain intensity, disability and ultrasound findings. It is better than corticosteroid injection by its ability to induce selfhealing and by its more sustained effect on the intermediate turn follow-up, with no side effects and no hypersensitivity. More studies are recommended to test the efficacy of PRP on the long term.

\section{Conflicts of interest:}

No conflicts of interest.

\section{References}

1- LEE H.J., KIM P.T., AMINATA I.W., HONG H.P., YOON J.P. and JEON I.H.: Surgical release of the first extensor compartment for refractory de Quervain's tenosynovitis: Surgical findings and functional evaluation using DASH scores. Clin. Orthop. Surg., 6 (4): 405-409, 2014.

2- PETERS -VELUTHAMANINAL C, WINTERS JC, GROENIER KH. and MAYBOOM-DEJONG B.: Randomized controlled trial of local corticosteroid injections for de Quervain's tenosynovitis in general practice. BMC. Musculoskel Disorders, 10: 131, 2009.

3- FOYE P.: Physical Medicine and Rehabilitation for De Quervain Tenosynovitis, Medscape, http://emedicine. medscape.com/article/327453- overview, 2016.

4- MENENDEZ M.E., THORNTON E., KENT S., KALAJIAN T. and RING D.: A prospective randomized clinical trial of prescription of full-time versus as-desired splint wear for de Quervaintendinopathy. Int. Orthop. 39 (8): 1563-1569, 2015.

5- MCDERMOTT J.D., ILYAS A M., NAZARIAN L.N. and LEINBERRY C.F.: Ultrasound-guided injections for de Quervain's tenosynovitis. Clin. Orthop. Relat. Res., 470 (7): 1925-1931, 2012.

6- IPPOLITO J.A., HAUSER S., PATEL J., VOSBIKIAN M. and AHMED I.: Nonsurgical treatment of De Quervain tenosynovitis: A prospective randomized trial. Hand, $1558944718791187,2018$.

7- FILARDO G., DI MATTEO B., KON E., MERLI G. andMARCACCI M.: Platelet-rich plasma in tendon-related disorders: Results and indications.KneeSurg Sports Traumatol. Arthrosc, 26: 1984, 2018.

8- ANITUA E., PRADO R., NURDEN A.T. and NURDEN P.: Characterization of Plasma Rich in Growth Factors (PRGF): Components and formulations. In: Anitua E., Cugat R., Sánchez M. (eds) Platelet Rich Plasma in Orthopaedics and Sports Medicine. Springer, Cham. Chapter II, 29-30, 2018.

9- AGRAWAL A.C. and KALIA R.B.: Platelet rich plasma in tendinopathies. Orthopaedic Journal of MP Chapter., $21(2), 2015$.

10- SUTHAR M., GUPTA S., BUKHARI S. and PONEMONE V.: Treatment of chronic non-healing ulcers using autol- ogous platelet rich plasma: A case series. Journal of biome dical science, 24 (1): 16, 2017.

11- WOLF J.M., STURDIVANT R.X. and OWENS B.D.: Incidence of de Quervain's tenosynovitis in a young, active population. J. Hand. Surg. Am., 34 (1): 112-5, 2009.

12- GOEL R. and ABZUG J.M.: De Quervain's tenosynovitis: a review of the rehabilitative options. Hand, 10 (1): 1-5, 2015.

13- FILARDO G., DI MATTEO B., KON E., MERLI G. and MARCACCI,M.: Platelet-rich plasma in tendon-related disorders: Results and indications. Knee. Surg. Sports. Traumatol. Arthrosc., 26: 1984, 2018.

14- CREANEY L., WALLACE A., CURTIS M. and CONNELL D.: Growth factor-based therapies provide additional benefit beyond physical therapy in resistant elbow tendinopathy: A prospective, single-blind, randomised trial of autologous blood injections versus platelet-rich plasma injections. British Journal of Sports Medicine, 45 (12): 966-971, 2011.

15- AL-ARDI I.M.: Platelet-rich plasma as a treatment for DE Quervain's Disease. AL-QADISIYAH MEDICAL JOURNAL, 13 (23): 197-201, 2017.

16- GLANZMANN M. and LAURENT AUDIGE': Plateletrich plasma for chronic lateral epicondylitis: Is one injection sufficient?, Arch. Orthop. Trauma. Surg., 135: 1637$1645,2015$.

17- FILARDO G., KON E., DI MATTEO B., DI MARTINO A., TESEI G., et al.: Platelet-rich plasma injections for the treatment of refractory Achilles tendinopathy: Results at 4 years, Blood Transfusion, 12 (4): 533-540, 2014.

18- MARDANI-KIVI M., KARIMIMOBARAKEH M., BAHRAMI F., HASHEMI-MOTLAGH K., SAHEBEKHTIARI K. and AKHOONDZADEH N.: Corticosteroid injection with or without thumb spica cast for De Quervain tenosynovitis. J. Hand. Surg. Am., 2014.

19- Jeyaraman M.: The Prospective Study on Efficacy and Functional Outcome of Autologous Platelet Rich Plasma Injection in Musculoskeletal Disorders. EC Orthopaedics, 9: 849-863, 2018.

20- AL-ARDI I.M.: Platelet-rich plasma as a treatment for DE Quervain's Disease. Al-Qadisiyah Medical Journal, 13 (23): 197-201, 2017.

21- SAHU A., SINGH P.K., KHAN S., SINGHANIA S., GUDHE M., MUNDADA G., et al.: Ultrasound-guided platelet-rich plasma infiltration: A stupendous treatment for chronic tendinopathy. Saudi Journal of Sports Medicine, 16 (3): 185, 2016.

22- YADAV R., KOTHARI S.Y. and BORAH D.: Comparison of local injection of platelet rich plasma and corticosteroids in the treatment of lateral epicondylitis of humerus. Journal of clinical and diagnostic research: JCDR, 9 (7): RC05, 2015.

23- ADAMS B.D., GROSLAND N.M., MURPHY D.M. and MCCULLOUGH M.: Impact of impaired wrist motion on hand and upper-extremity performance. The Journal of Hand Surgery, 28 (6): 898-903, 2003.

24- ALLAM A.E.S., AL-ASHKAR D.S., NEGM A.A., ELTAWAB B.A., WU W.T. and CHANG K.V.: Ultrasoundguided methotrexate injection for De Quervaindisease of 
the wrist: What lies beyond the horizon? Journal of Pain Research, 10: 2299, 2017.

25- KAMEL M., MOGHAZY K., EID H. and MANSOUR R.: Ultrasonographic diagnosis of de Quervain's tenosynovitis. Annals of the rheumatic diseases, 61 (11): 10341035, 2002.
26- ORLANDI D., CORAZZA A., FABBRO E., FERRERO G., SABINO G., SERAFINI G., et al.: Ultrasoundguided percutaneous injection to treat de Quervain's disease using three different techniques: A randomized controlled trial. European Radiology, 25 (5): 1512-1519, 2015.

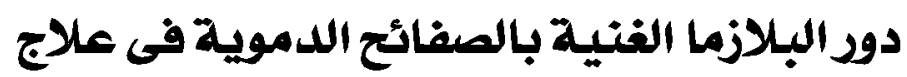

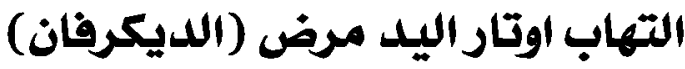

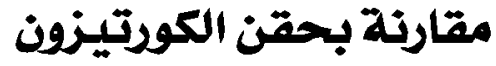

\author{
التهاب دى كرفان لفمد الاوتار هو التهاب الاوتار الموجودة على جانب الرسخ فوق قاعدة الابهام، وهى اوتار العضلات المسئولة عن فرد

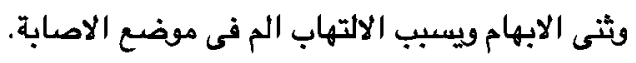 \\ اثبتت الدراسات أن الكوتيزنف يستخدم مؤقتا لازالة الالام وإكتة لا يوفر الالتئام الدائم بعكس حقن البلازما التى تقوى وتدعم الاوتار. \\ وهناك اجما ع على الدود الايجابى لحقن عوامل النمو والبلازما المدعم بالصفائح وفاعليتة خصوصا على الاوتار.

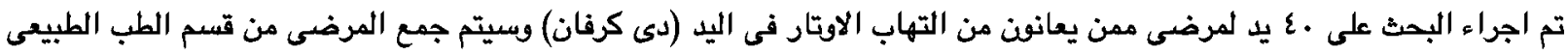

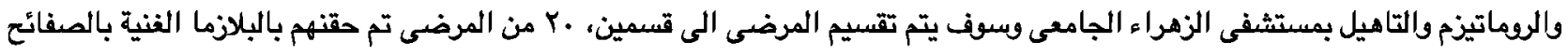 \\ الدموية، والاخرين تم حقنهم بمادة الكورتينون.

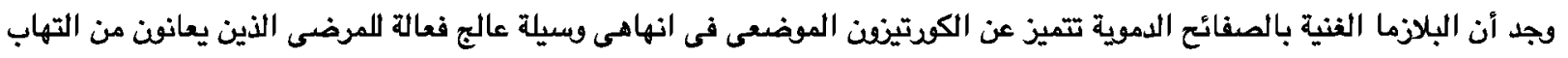

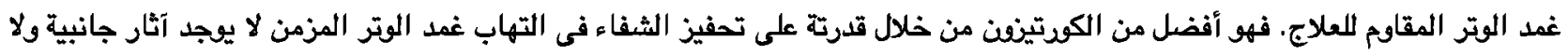

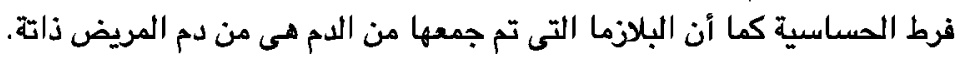

